络合物。

所有上述络合物 (I)-(VI) 的红外光谱，校磁 共振谱以及碳氢分析数据与预期的结构相符。核磁 共振谱表明该类型络合物一般包含两三种空间异构 体. 例如甲基络合物 (1) 有三种异构体. 通过它的 'HNMR 的甲基化学位移值和积分值可以确定络合 物(I)中三种昇构体的比例是 ea:ce: ae $=1: 7.6: 9.6$.
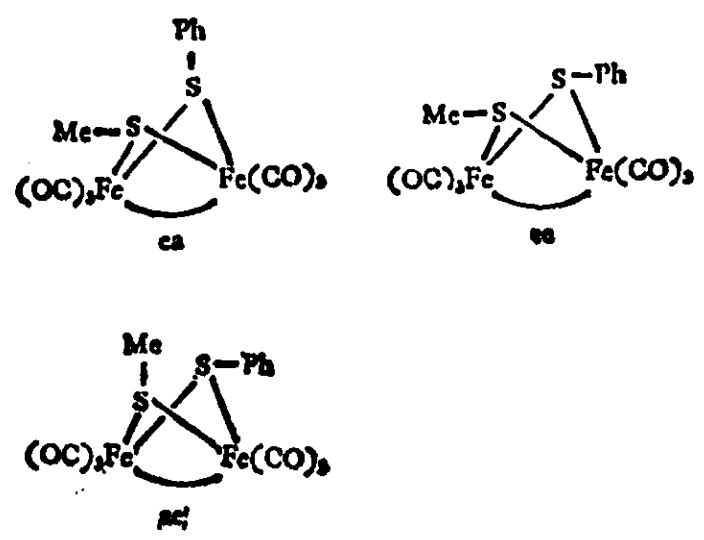

$(\mu-\mathrm{PhS})\left(\boldsymbol{\mu}-\mathrm{CH}_{2} \mathrm{~S}\right) \mathrm{Fe}_{2}(\mathrm{CO})$ ，的三种空间异构体
除正丁基络合物 (v) 是红色油状物外，其余五 个为具有一定熔点的红色晶体。

此外，我们对中间体 $(\mu-\mathrm{PhS})(\mu-\mathrm{LiS}) \mathrm{Fe}_{2}(\mathrm{CO})$ 。 同各种卤代烃的亲核取代反应活性进行了研究。以 贞代正 $\mathrm{J}$ 烷为反应物可比较卤意的影响。当反应条 件(反应物克分子比，反应温度和时间）以及后处理 条件相同时,由嗱代正丁㜔得到的络合物 (v) 产率

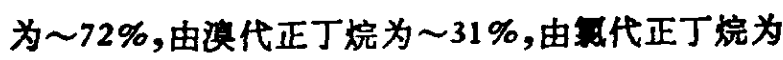
$\sim 9 \%$. 显然卤紊在此亲核取代反应中的活性次序 为: 一I»-Br》-Cl. 至于备代烃中烃基对反应活 性的影响则不如囟亲显著. 在用几种磺代烃的实验 中, 由于炤基不同所得到的络合物 ( $\mathrm{I}$ 至 ( $\mathrm{V}$ ) 的产 率在 72-86\% 之间，其波动范围仅约 $14 \%$ 。 篮于 澳代及每代烃(丙烯位㐫代物除外)在此反应中的活 性太低,合成该类型络合物以用盒代烃为宜.

\section{朱礼成刘向阳胡音眉王积涛 （南开大学化学系，天渾）}

\title{
促进人参种子萌发的新方法
}

人参 (Panax ginseng C.A. Mey.) 是我国名贵 药材. 其种子休眠期长,收获时种胚尚未发育完全, 而要经历由高温至低温的顺序过程, 即先在较高的 温度条件下 $\left(20 \sim 12{ }^{\circ} \mathrm{C}\right)$ 形态上的发育完成后,再经 0 $5^{\circ} \mathrm{C}$ 低温层积处理 3 4 个月完成生理后㜪,至次 年春季才能萌发,如果得不到上述所管条件,往往延 迟到第三年春季才能萌发出苗, 给人参生产带来一 定困难.

迄今已有大量有关人参种子休眠萌发的报道，

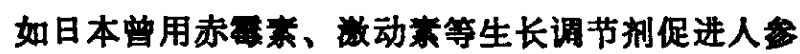
种子后熱, 使低温期缩短一半时间. 我们根据前人 认为人种于含有 $\mathrm{ABA}$ 类抑制剂和缺少赤露素类泚 等物质，以及近年来种子休眠理论的新进展,设计了 人种子用流水冲洗 15、30 天后用赤繁美 200ppm、

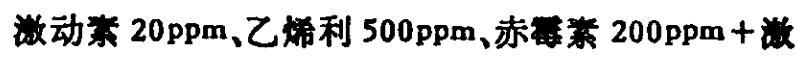
动䒺 $20 \mathrm{ppm}+乙$ 乙掵利 $500 \mathrm{ppm}$ 浸种 2 天及对照等处 理, 试猃于 1982 年 8 月 13 日在北京进行, 种子经 处理后沙藏室外时间平均土温 $23.5^{\circ} \mathrm{C}$ 沙中含水量 $20 \%$ 左右,至 11 月 23 日即转入温室内, 在此之前仅
有 10 天时间是处于 $5^{\circ} \mathrm{C}$ 左右的土温条件, 温室平均 土温 $11.5^{\circ}$, 至 12 月 8 日开始出苗. 经冲洗后用

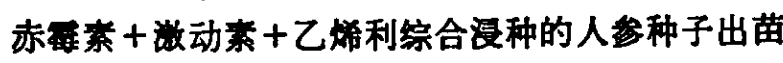
率达 42.5 46\%, 单用多种激系综合处理, 但末经 冲洗的出苗 $28.4 \%$ ，其它处理除赤霜来仅个别出苗 (2.5 7.5\%) 外, 哏对照一样均未出苗. 以上结果 说明人参种子有可能在人为空制下不经低温而发 芽,种胚后熟期从原来 8 个月左右缩短为 4 个月,这 是从未报道过的. 由此证实流水冲洗能消除人参种 子内含有的抑制发芽物质,再补充以多种做意，可以 大大促进种子萌发. 至于机制问题似乎比现有的标 念更为复杂一些. 此项工作正在继续进行之中, 预 期将为人参播种育苗提供新方法, 并为深人探索休 眠机制提供线索.

\section{陈 摸 孙昌高 (中国医学科学院药物研究所, 北京) \\ 郑光华 \\ （中国科学院植物研究所，北京）}

